\title{
Silicon carbide against silicon : a comparison in terms of physical properties, technology and electrical performance of power devices
}

\author{
M. L. Locatelli and S. Gamal \\ CEGELY. E.C.P.A., URA CNRS n 829, INSA Lyon, Bât. 401, 20 avenue A. Einstein, \\ 69621 Villeurbanne Cedex. France
}

(Reçeived 9 June 1992, revised 29 January 1993, accepted 5 February 1993)

\begin{abstract}
The aim of the present paper is to give the state of the art of the silicon carbide technology by «photographing » it beside the unique technology used for power electronics that is the silicon one. The theoretical superiority of SiC physical properties on those of $\mathrm{Si}$, together with the important technological advancements realized during the last decade, are the main reasons of the interest given to $\mathrm{SiC}$ nowadays. Concerning electrical performance, the voltage and power handling capabilities do not reach today the high expected values, and remain lower than those provided by Si. On the other hand, $\mathrm{SiC}$ components confirm the aptitude of this material for high temperature and high frequency applications.
\end{abstract}

\section{Introduction.}

In order to meet the requirements of modern power electronic applications, the trends for power semiconductor devices are higher voltage, frequency and power handling capabilities, as also greater compactness of systems, obtainable by an increased integration or a reduction of cooling means.

Among known semiconductor materials, solely silicon is used today for power device manufacturing. Equally studied for a long time [1] (but sometimes in an irregular way [2]), silicon carbide has becoming an important research activity all over the world during the last decade $[3,4]$.

The present paper wants to report the state of the art of this new silicon carbide technology, comparing it to the conventional silicon one. Three main paragraphs will confront successively the physical properties of each of two semiconductors, the current ability of their respective technologies, together with the electrical performance exhibited by the devices available today. In particular, this third part will present the results of our comparative experimental study of two ultra-fast diodes of $400 \mathrm{~V}$ breakdown voltage, one diode being in $\mathrm{Si}$, the other being in SiC. The purpose is to show the reasons of the present interest in silicon carbide, giving also some needed informations to evaluate its chance to win a share of the power device market. 


\section{Comparison of the physical properties of Si and SiC.}

Table I compiles the principal physical parameters we need to compare the theoretical potentialities of silicon and silicon carbide with regard to power electronics. In effect, the term of silicon carbide gathers more than one hundred of different crystalline stacking forms. However, only the two structures principally considered for electronics, that is to say $3 \mathrm{C}-\mathrm{SiC}$ (the only cubic form) and $6 \mathrm{H}-\mathrm{SiC}$ (a hexagonal form), are presented here. All issued from literature, the properties in table I are given at $27^{\circ} \mathrm{C}$, and their values correspond either to theoretical evaluations or to the best experimental published results.

Table I. - Physical parameters of different undoped semiconductors at $27{ }^{\circ} \mathrm{C}$ with $E_{\mathrm{g}}$. energy bandgap. $\varepsilon_{\mathrm{r}}$ : relative permittivity. $\mu_{\mathrm{n}}, \mu_{\mathrm{p}}$. low-field electron and hole mobilities. $v_{\text {sat }}$. scattering limited saturated velocity. $E_{\mathrm{M}}$. electric field strength at breakdown. $\lambda$ : thermal conductivity. $n_{1}$ : intrinsic carrier concentration.

\begin{tabular}{|c|c|c|c|c|c|c|c|c|}
\hline Material & $\begin{array}{c}E_{\mathrm{g}} \\
(\mathrm{eV})\end{array}$ & $\varepsilon_{\mathrm{r}}$ & $\begin{array}{c}\mu_{\mathrm{n}} \\
\left(\mathrm{cm}^{2} / \mathrm{Vs}\right)\end{array}$ & $\begin{array}{c}\mu_{\mathrm{p}} \\
\left(\mathrm{cm}^{2} / \mathrm{Vs}\right)\end{array}$ & $\begin{array}{c}v_{\text {sat }} \\
(\mathrm{cm} / \mathrm{s})\end{array}$ & $\begin{array}{c}E_{\mathrm{M}} \\
(\mathrm{V} / \mathrm{cm})\end{array}$ & $\begin{array}{c}\lambda \\
\left(\mathrm{W} / \mathrm{cm}^{\circ} \mathrm{C}\right)\end{array}$ & $\begin{array}{c}n_{1} \\
\left(\mathrm{~cm}^{-3}\right)\end{array}$ \\
\hline $\mathrm{Si}$ & 1.12 & 11.9 & 1500 & 470 & $10^{7}$ & $3.7 \times 10^{5}$ & 1.5 & $1.45 \times 10^{10}$ \\
\hline $6 \mathrm{H}-\mathrm{SiC}$ & 2.9 & 10 & 460 & 50 & $2 \times 10^{7}$ & $2.2 \times 10^{6}$ & 5.0 & $3.0 \times 10^{-5}$ \\
\hline $3 \mathrm{C}-\mathrm{SiC}$ & 2.2 & 9.7 & 800 & 50 & $2.5 \times 10^{7}$ & $1.5 \times 10^{6}$ & 5.0 & 5.0 \\
\hline
\end{tabular}

A simple survey of these data, just as they are, already allows to underline some advantages of $\mathrm{SiC}$ in respect to $\mathrm{Si}$. We first consider the bandgap $E_{\mathrm{g}}$, that is the principal characteristic of any semiconductor material. This quantity, monitoring the concentration of intrinsic carriers present in the material, influences greatly the value of the leakage current through any reverse biased p-n junctions. To minimize these reverse currents (rapidly increasing with temperature), a low value of the intrinsic carrier density is required. At a given temperature, such a condition is better satisfied when the value of $E_{\mathrm{g}}$ is higher. Figure 1 represents the dependence of the intrinsic carrier concentration on temperature for $\mathrm{Si}, 3 \mathrm{C}-\mathrm{SiC}$ and $6 \mathrm{H}-\mathrm{SiC}$. With a $E_{\mathrm{g}}$ that can be 2 or 3 times larger than that of $\mathrm{Si}, \mathrm{SiC}$ enhances the junction temperature limitation bound to $\mathrm{Si}$ (conventionally situated at $200^{\circ} \mathrm{C}$ ) by few hundreds of Celsius degrees (up to about $650^{\circ} \mathrm{C}$ ). This property of $\mathrm{SiC}$, together with its good thermal stability awards it a particular interest from high temperature applications. However, the use of a large bandgap semiconductor is penalizing because it results in a high voltage drop on forward biased $\mathrm{p}-\mathrm{n}$ junctions. This fact represents the main theoretical drawback of $\mathrm{SiC}$ compared to $\mathrm{Si}$. But silicon carbide exhibits advantages even at conventional junction temperature. Thus, breakdown electric field $E_{\mathrm{M}}$ of SiC, 4 to 6 times higher than that of $\mathrm{Si}$ at $27^{\circ} \mathrm{C}$ shows that $\mathrm{SiC}$ is well suited for voltage capability enhancement of devices. In fact, for unipolar as for bipolar devices, SiC will allow higher breakdown voltage than $\mathrm{Si}$ does, for equivalent layer widths. Besides, the excellent thermal conductivity $\lambda$ of $\mathrm{SiC}$ (more than 3 times that of $\mathrm{Si}$ ) is advantageous to reduce the problems of heat sinking, and enhances power handling capability.

Some publications suggest more elaborated studies of semiconductor potentialities defining some figures of merit. Depending on fundamental physical parameters, they are used as 


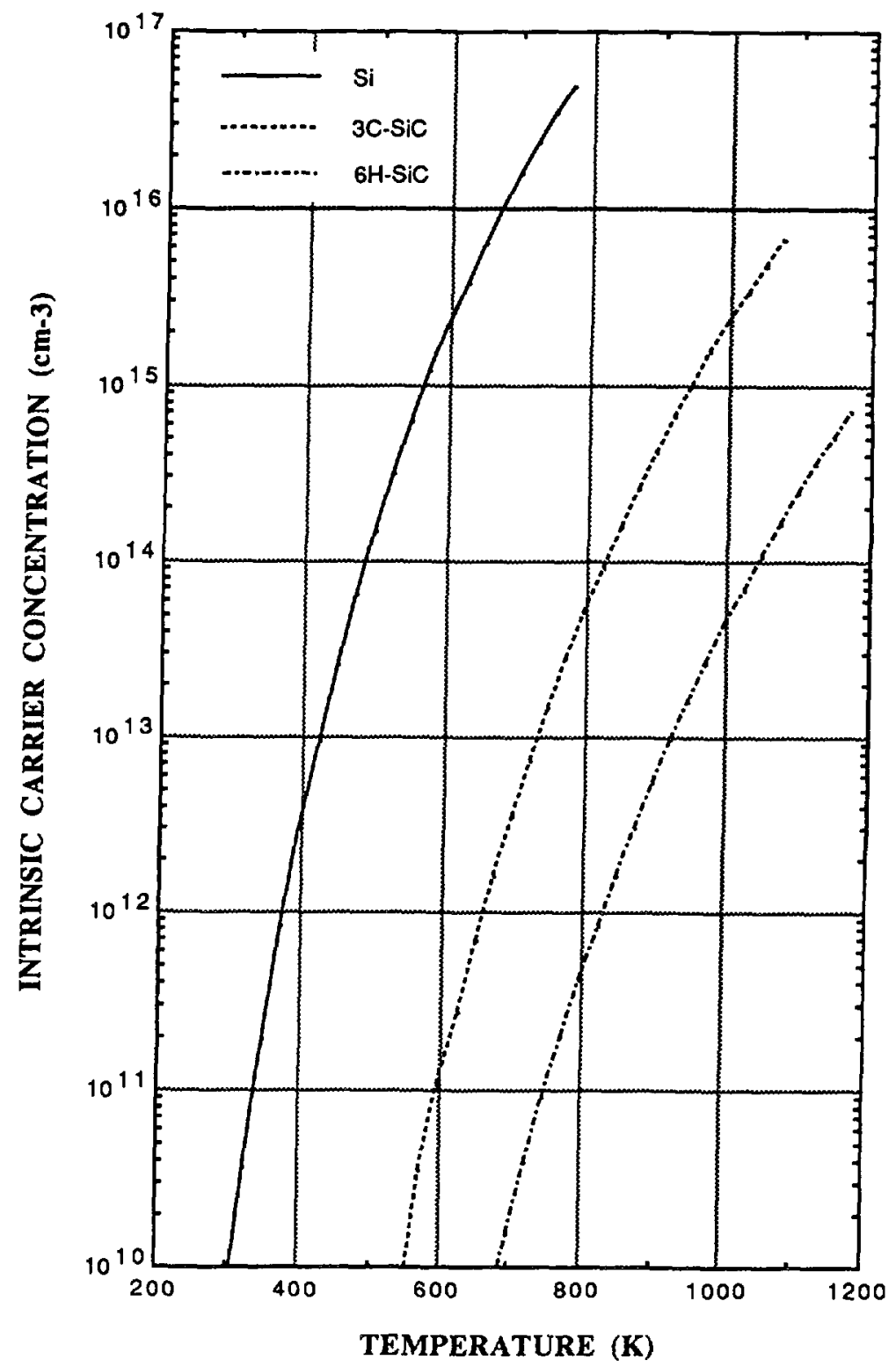

Fig. 1. - Temperature dependence on the intrinsic carrier concentration of Si, $3 \mathrm{C}-\mathrm{SiC}$ and $6 \mathrm{H}-\mathrm{SiC}$.

criterions of comparison with regard to such or such device characteristic. Among them the figure of merit of Baliga [5] given by the following expression :

$$
\mathrm{BFM}=\varepsilon \mu_{\mathrm{n}} E_{\mathrm{M}}^{3}
$$

corresponds, for a given voltage capability, to the on-state conductance per area of a unipolar power device with negligible channel resistance. In spite of a lower mobility, the BFM of $\mathrm{SiC}$ is 50 times higher than that of $\mathrm{Si}$ at $27^{\circ} \mathrm{C}$. This allows us to forsee the feasibility of high voltage MOSFET's and Schottky diodes with lower forward voltage drops than those obtained 
with Si devices [6]. Moreover, these unipolar devices will also exhibit a required layer for high voltage handling much thinner and less lightly doped than it is allowed by $\mathrm{Si}$, which means from a technological point of view, greater easiness in device fabrication.

Schlangenotto et al. [7] consider the trade-off between the on-state and the switching performances for these same unipolar devices. The figure of merit they defined is given by the relation :

$$
\mathrm{SFM}=\mu_{\mathrm{n}} E_{\mathrm{M}}^{2}
$$

They show this quantity is proportional to the ratio of the on-state conductance to the stored charge which is necessary for the on-conductance on the one-hand and inversely proportional to the product of the on-state losses and the switching-off losses of a MOFSET on the other hand. The SFM of SiC being 11 times higher than that of $\mathrm{Si}, \mathrm{SiC}$ improves the compromise between forward voltage drop and switching speed.

We can finally give the Johnson's figure of merit [8] defined by :

$$
\mathrm{JFM}=v_{\text {sat }}^{2} E_{\mathrm{M}}^{3} .
$$

It estimates the semiconductor potentiality for frequency enhancement both with remaining high blocking voltage capability. The $\mathrm{SiC}$ superiority on $\mathrm{Si}$ in this field is remarkable (the ratio JFM(SiC)/JFM(Si) being higher than 100).

So the previous considerations provide the reasons of the research related to silicon carbide for more than thirty years. However, though silicon allowed large scale production of electronic devices more and more efficient during that time, the coming out of low and medium power SiC components is only very recent. The last developments in process technology justify the renewed interest given to SiC. That technological point of view and the feasibility of an industrial production will be discussed in next section.

\section{Comparison of technological state-of-the art of $\mathrm{Si}$ and $\mathrm{SiC}$.}

The success of reproducible single crystal growth since 1983 [9, 10] has removed a major obstacle to the progress of $\mathrm{SiC}$ technology. Consider first the wafer production. The modified method of Lely [9] permits today the production of $6 \mathrm{H}-\mathrm{SiC}$ single crystals with acceptable quality. The obtained ingots, being of diameter about 1 inch (silicon wafers can have diameters of 8 inches) and growth rate of $4 \mathrm{~mm} / \mathrm{h}$, can be used for electronic device fabrication, in spite of being very expensive. It should be also noted that the unintentionally doped materials are of n-type with a minimum doping concentration of $10^{16} \mathrm{~cm}^{-3}$, while for silicon technology doping concentrations as low as $5 \times 10^{13} \mathrm{~cm}^{-3}$ are possible.

For epitaxial thin films (another method for single crystal production), the vapour phase CVD is the main applied method. The first successful deposited films were $3 \mathrm{C}-\mathrm{SiC}$ on $\mathrm{Si}$ substrates. The evolution of this technique allows the production of films up to $30 \mu \mathrm{m}$ (the maximum corresponding epitaxial silicon films are of about $150 \mu \mathrm{m}$ thickness). In spite of the evident advantages of silicon as substrates, the obtained epitaxial 3C-SiC suffer from important structure defects due to mismatch of lattice constants between $3 \mathrm{C}-\mathrm{SiC}$ and $\mathrm{Si}$ and the difference in their thermal expansion coefficients. On the other hand, the epitaxial $6 \mathrm{H}-\mathrm{SiC}$ layers on $6 \mathrm{H}-\mathrm{SiC}$ substrates are of better quality, specially from the point of view of acceptor compensation which is reduced to about $2 \%$ in this case. However, the highest acceptor impurity concentration available today for p-type epitaxial layer is limited to about $5 \times 10^{18} \mathrm{~cm}^{-3}$. The unintentionally doped films are also of n-type. In fact, the growth mechanisms, the nature of defects and contaminants are still uncompletely understood.

The many $\mathrm{SiC}$ device prototypes already realized $[14,16]$ show the feasibility of the main 
technological processes necessary for device fabrication. Many technological processes common to silicon are applicable to $\mathrm{SiC}$, as for example the use of $\mathrm{SiO}_{2}$ as a gate oxide or mask for other fabrication steps. Some particularities should however be mentioned. For instance, the impurity diffusion in $\mathrm{SiC}$ requires very high temperature and is not pratical. The doping is therefore realized during crystal growth or by ion implantation followed by thermal annealing. Actually, p-type doping by ion implantation presents more difficulties than n-type doping. On the other hand, etching is usually made by reactive ion etching because $\mathrm{SiC}$ is inert to classical chemical solutions. Moreover, the realization of good ohmic contacts is a crucial step. Whatever the metal (or metal combination) is used, the specific resistances are never below $10^{-4} \Omega \cdot \mathrm{cm}^{2}$, that is to say 10 to 100 greater than those obtained for silicon. The physicochemical nature of the contact products depends on the temperature, the polytype and the lattice orientation of the substrate (intermixing producing silicides or carbides at the $\mathrm{SiC}$ /metal interface have been reported). Its evolution with increasing temperature leads to increased contact specific resistances [12], and creates reliability problems. An excellent review on all these different subjects can be found in [13] and [15]. In the following section, the test of some issued $\mathrm{SiC}$ devices shows the still more required optimization of different technological steps.

\section{Comparison of the electrical performance of power $\mathrm{Si}$ and $\mathrm{SiC}$ devices.}

The actual silicon technology allows the realization of bipolar, unipolar as well as mixed device structures which satisfy the needs of many applications for high current, high voltage and high frequency capabilities. The covered ranges of $[I, V, f]$ are approximately [5 kA, $10 \mathrm{kV}, 10 \mathrm{MHz}$. The main limitation of silicon, which is related to its intrinsic bandgap, is the high temperature device performance.

For silicon carbide, some devices classified as power devices recently appeared, proposed by an unique American source [13]. They are p-n junction diodes and Schottky diodes [14, 15]. The p-n junction diodes are of $400 \mathrm{~mA}$ forward current and $400 \mathrm{~V}$ breakdown voltage with maximum junction temperature of $350{ }^{\circ} \mathrm{C}$. The Schottky diodes are $1 \mathrm{~A}, 60 \mathrm{~V}$ and $300{ }^{\circ} \mathrm{C}$. Also blue LED's have been commercialized for many years in Germany and Japon. Many other low power device prototypes have been developed as JFET, MOSFET and MESFET. If ever mentioned, the reliability aspect is often restricted to the publication of a time of operation during which the electrical characteristics of the device under test are not degraded. Durations in the order of one thousand hours are generally reported. In spite of the relative advancement of $\mathrm{SiC}$ technology during the last decade, the problem of resistive ohmic contacts as well as the high forward voltage drop of p-n junctions limit the high current capabilities of bipolar devices. The difficulty of production of homogeneous large section area limits both the high current and high voltage capabilities. The relatively high value of the minimum $n$-type doping concentrations $\left(10^{16} \mathrm{~cm}^{-3}\right)$, together with the low available epitaxial layer thicknesses [13], also limit the high voltage capability. Moreover, the impossibility to perform doping using diffusion technics prevents the realization of structures presenting deep wells. In fact, the unique means to locally dope a $\mathrm{SiC}$ layer is ion implantation, and the deepness of the doped regions obtained are very thin. This supplementary technological restraint increases the complexity of the $\mathrm{SiC}$ power device fabrication. Finally, it should be noted that the maximum permissible temperature of $350^{\circ} \mathrm{C}$ is due to the lack of encapsulation and packaging suitable for higher temperatures $[14,16]$.

Now, we present our own comparative experimental study of silicon and silicon carbide diodes [17] in order to clarify the real inconvenients and advantages of those devices. We tested only one type of SiC diodes, manufactured by Cree [13], and the results showed here are representative of the measurements performed on three samples. All these three SiC diodes 
exhibited the same electrical behaviour. The power losses of the diodes have been measured in a ramp switching where the diodes were initially in forward conduction during a time period $t_{0}$ and then reverse biased by a voltage source $V_{\mathrm{R}}$ in series with a self inductance $L$ for a time period $T-t_{0}$ as shown in figure 2 . Pulse width between 20 and $60 \mu$ s and duty cycles ranging from 0.3 to $0.5 \%$ were used in order to avoid self-heating. The diode temperature was controlled by a hot air flow system (TP041AH from Temptronic). Commutation power losses in each diode have been compared under the same switching conditions of forward current before switching $\left(50 \mathrm{~A} / \mathrm{cm}^{2}\right)$, applied reverse voltage $(100 \mathrm{~V})$ and rate of current density decrease $\left(9000 \mathrm{~A} /\left(\mathrm{cm}^{2} . \mu \mathrm{s}\right)\right)$ and for temperatures between $30^{\circ} \mathrm{C}$ and $300{ }^{\circ} \mathrm{C}$. Being very fast with a reverse recovery time $t_{\mathrm{rr}}$ of $41 \mathrm{~ns}$ at room temperature under the above mentioned switching conditions, the $\mathrm{SiC}$ diode has been compared with a very fast commercial silicon diode (its $t_{\mathrm{rr}}$ is $18 \mathrm{~ns}$ under the same switching conditions).

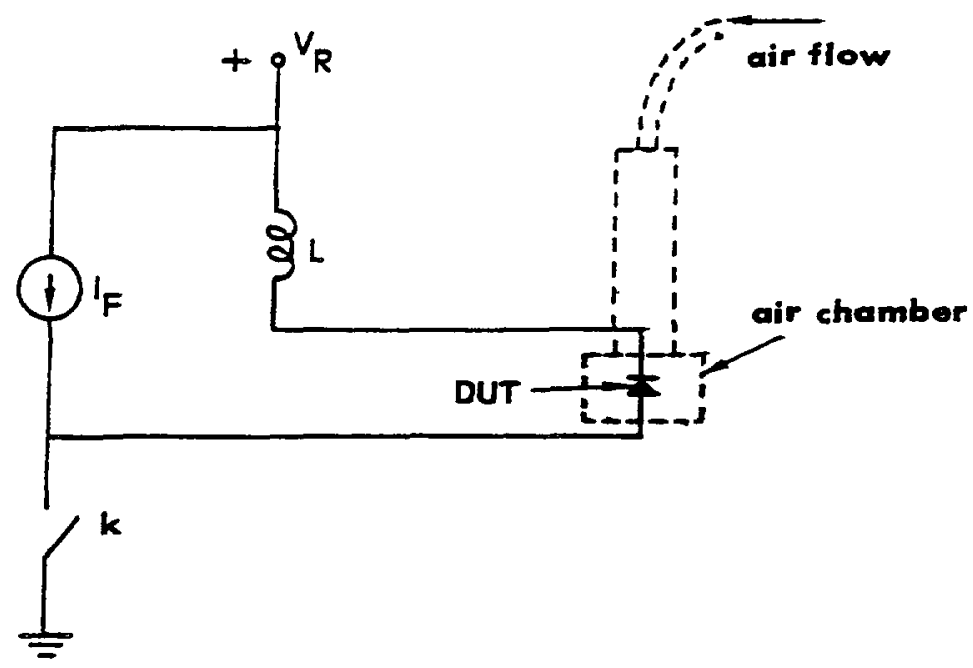

a)

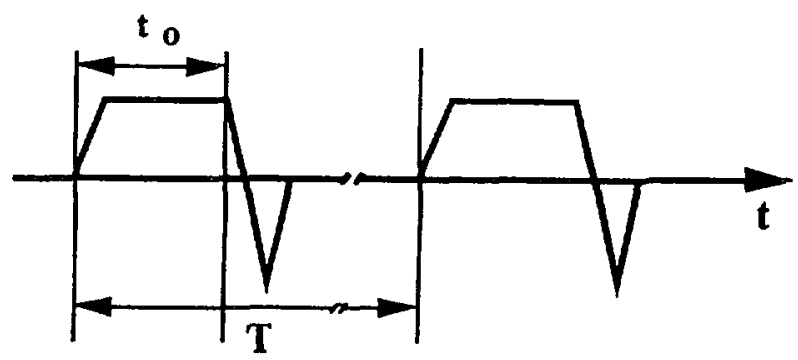

b)

Fig. 2. - Experimental set-up : (a) basic test circuit and (b) current waveform.

Figure 3 shows that the ratios between the power losses in the SiC diode to that in Si diode as function of the junction temperature. The forward conduction losses are always greater for the $\mathrm{SiC}$ diode. In fact, this is due to the high forward voltage drop of the $\mathrm{SiC}$ diode as shown in figure 4 , in spite of its decrease with temperature. Figure 3 also shows that although the 


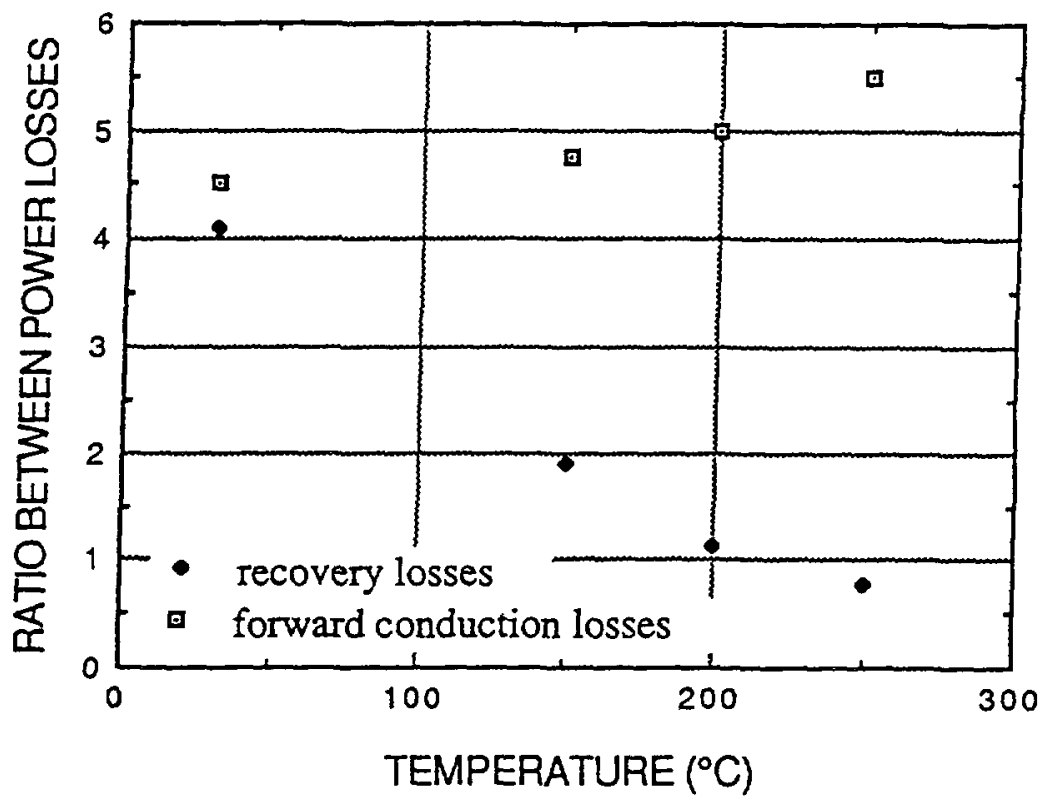

Fig. 3. - Ratios between power losses per unit area in SiC diode to that of Si diode as functions of junction temperature.

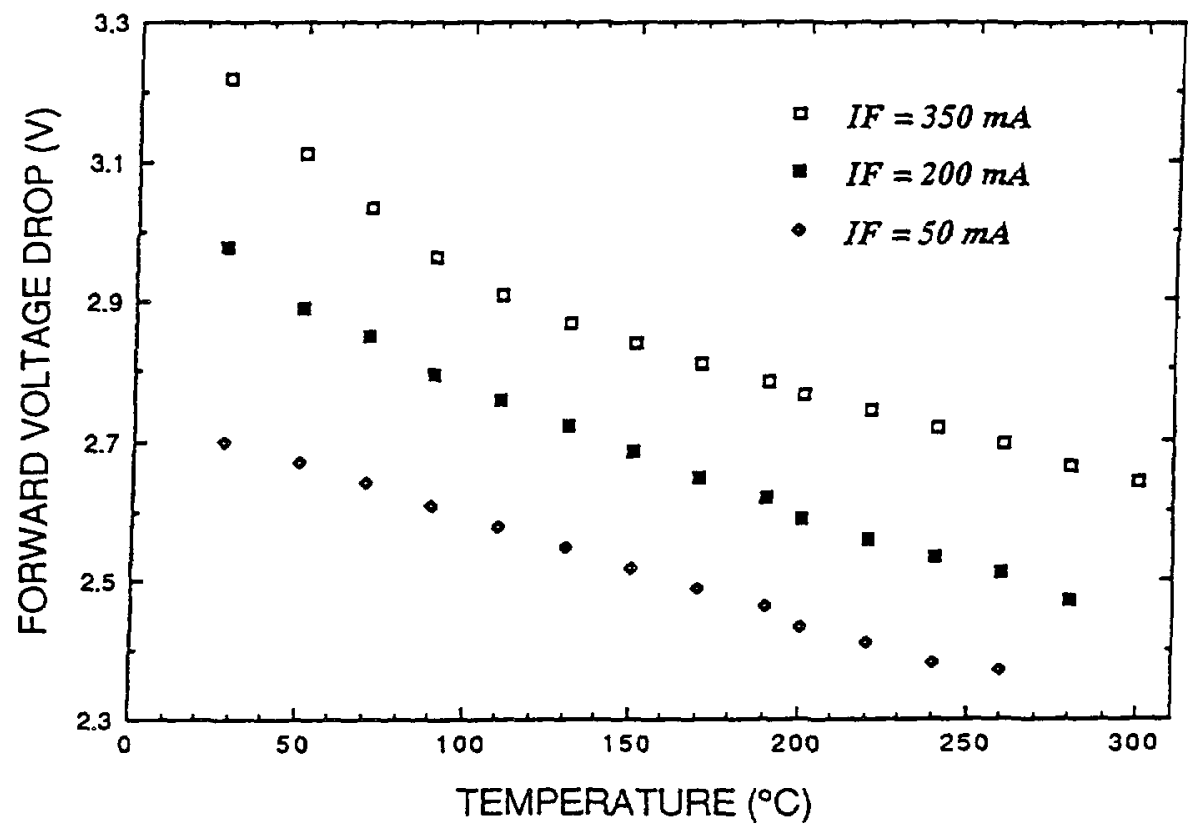

Fig. 4. - The forward voltage drop of the $\mathrm{SiC}$ diode for different forward currents. 
Table II. - SiC-research centers in the world.

\begin{tabular}{|c|c|c|}
\hline EUROPE & USA & JAPAN \\
\hline $\begin{array}{l}\text { A.F. Ioffe Physico- } \\
\text { Technical Institute } \\
\text { Academy of Sciences } \\
\text { Saint-Petersburg - Russia }\end{array}$ & $\begin{array}{l}\text { North Carolina State } \\
\text { University } \\
\text { Raleigh - North Carolina }\end{array}$ & $\begin{array}{l}\text { Electrotechnical } \\
\text { Laboratory } \\
\text { Niihari-gun, Ibaraki }\end{array}$ \\
\hline $\begin{array}{l}\text { Fraunhofer - Institut } \\
\text { Freiburg - Germany }\end{array}$ & $\begin{array}{l}\text { Purdue University } \\
\text { West Laffayette - Indiana }\end{array}$ & $\begin{array}{l}\text { Kyoto University } \\
\text { Kyoto }\end{array}$ \\
\hline $\begin{array}{l}\text { GEPRA - CEGELY } \\
\text { National Institute of } \\
\text { Applied Sciences } \\
\text { Lyon - France }\end{array}$ & $\begin{array}{l}\text { University } \\
\text { of Pittsburgh } \\
\text { Pittsburgh - Pennsylvania }\end{array}$ & $\begin{array}{l}\text { Hitachi Corporation } \\
\text { Musashino - Tokyo }\end{array}$ \\
\hline $\begin{array}{l}\text { Institut A für } \\
\text { Wertstoffkunde } \\
\text { Hannover - Germany }\end{array}$ & $\begin{array}{l}\text { University of Virginia } \\
\text { Charlottesville - V.A. }\end{array}$ & $\begin{array}{l}\text { Matsushita Research } \\
\text { Laboratories } \\
\text { Moriguchi - Osaka }\end{array}$ \\
\hline $\begin{array}{l}\text { Linköping University } \\
\text { Linköping - Sweden }\end{array}$ & $\begin{array}{l}\text { Cree research, Inc. } \\
\text { Durham - North Carolina }\end{array}$ & $\begin{array}{l}\text { Nissan } \\
\text { Research Center } \\
\text { Natsushima - cho. Yokosuka }\end{array}$ \\
\hline $\begin{array}{l}\text { Universität Erlangen- } \\
\text { Nürnberg } \\
\text { Erlangen - Germany }\end{array}$ & $\begin{array}{l}\text { NASA Lewis Research } \\
\text { Center } \\
\text { Cleveland - Ohio }\end{array}$ & $\begin{array}{l}\text { Sanyo Electric Co. } \\
\text { Osaka }\end{array}$ \\
\hline $\begin{array}{l}\text { LETI - CENG } \\
\text { Grenoble - France }\end{array}$ & $\begin{array}{l}\text { Naval Research } \\
\text { Laboratory } \\
\text { Washington - D.C. }\end{array}$ & $\begin{array}{l}\text { Sharp Corporation } \\
\text { Ichinomoto - Tenri - Nara }\end{array}$ \\
\hline $\begin{array}{l}\text { Dalmier-Benz A.G., } \\
\text { Research Institute } \\
\text { Frankfurt/Main }\end{array}$ & $\begin{array}{l}\text { Westinghouse } \\
\text { Research } \\
\text { and Development } \\
\text { Center } \\
\text { Pittsburgh - Pennsylvania }\end{array}$ & $\begin{array}{l}\text { Toshiba Corporation } \\
\text { Kawasaki - Kanagawa }\end{array}$ \\
\hline $\begin{array}{l}\text { Merlin Gerin } \\
\text { Grenoble - France }\end{array}$ & & $\begin{array}{l}\text { Toyota Central } \\
\text { Research Labs., Inc. } \\
\text { Aichi-gun - Aichi }\end{array}$ \\
\hline $\begin{array}{l}\text { Siemens A.G. } \\
\text { München - Germany }\end{array}$ & & \\
\hline
\end{tabular}


recovery losses in the $\mathrm{SiC}$ diode are important at low temperature, these losses become greater for the silicon diode than for temperatures higher than $220^{\circ} \mathrm{C}$. From these results and as the switching losses are proportional to the frequency, we conclude that the SiC diode is more suitable for high temperature and high frequency applications.

The comparison of power losses in the off-state clearly confirms the low reverse current in $\mathrm{SiC}$ diode with respect to the $\mathrm{Si}$ one even at high temperature, as can be expected for a wide bandgap material as silicon carbide. At room temperature, the current densities in $\mathrm{SiC}$ and $\mathrm{Si}$ diodes were $2 \times 10^{-8} \mathrm{~A} / \mathrm{cm}^{2}$ and $5 \times 10^{-5} \mathrm{~A} / \mathrm{cm}^{2}$, respectively, while at $200{ }^{\circ} \mathrm{C}$, they were $3.9 \times 10^{-7} \mathrm{~A} / \mathrm{cm}^{2}$ and $2.5 \times 10^{-3} \mathrm{~A} / \mathrm{cm}^{2}$, respectively. In fact, while silicon cannot be used for temperatures higher than $300{ }^{\circ} \mathrm{C}$ due to high reverse current, silicon carbide represents a mean for having devices working up to $600^{\circ} \mathrm{C}$.

\section{Conclusion.}

The superiority of the theoretical physical potentiality of silicon carbide with respect to silicon for power electronic applications is already a well known fact. The technological progress of $\mathrm{SiC}$ realized during the last decade encourages the research activity in the field of device development. However the commercially appeared SiC devices show that the complete potentiality of SiC has not been yet reached, specially in the field of high voltage and high power devices, where the performance of silicon devices is still better. Contrary, the realized $\mathrm{SiC}$ devices confirm the aptitude of this material for high temperature applications (higher than $250^{\circ} \mathrm{C}$ ). To further improve the performance of $\mathrm{SiC}$ power devices many research efforts are still required, especially concerning the characteristics of basic material, but also in order to get over technological obstacles remaining in the component fabrication line. The important number of research centers working nowadays on SiC technology (see the principal ones in Tab. II) and devices is a major prooth of the interest in this field.

\section{References}

[1] Nelson W. E. et al., Growth and Properties of $\beta$-SiC Single Crystals, IEEE J. Appl. Phys. 37 (1966) 333-336.

[2] Campbell R. B., Whatever Happened to Silicon Carbide, IEEE Trans. Indust. Elect. IE-29, n 2 (May 1982).

[3] Davis R. F. et al., A Review of the Status of Diamond and Silicon Carbide Devices for HighPower, -Temperature, and -Frequency Applications, Conf. IEDM 90, pp. 785-788.

[4] Matsunami H., Semiconductor Silicon Carbide. Expectation for Power Devices. Proc. of 1990 ISPSD \& ICs. Tokyo (1990) pp. 13-18.

[5] Shenal K. et al., Optimum Semiconductor for High-Power Electronics, IEEE Trans. Electron Devices 36, $\mathrm{n} 9$ (Sept. 1989).

[6] Bhatnagar M. et al., Analysis of Silicon Carbide Power Device Performance, Proc. of 1991 ISPSD \& ICs. pp. 176-180.

[7] Schlangenotto H. et al., Switching Properties of Power Devices on Silicon Carbide and Silicon, EPE-MADEP Conference (Florence, 2-6 Sept., 1991).

[8] Johnson E. O., Physical limitations on Frequency and Power Parameters of Transistors, RCA Rev. (1965) pp. 163-167.

[9] TAIRov Y. M. et al.. General Principles of Growing Large-Size Single Crystals of Various $\mathrm{S}_{1} \mathrm{C}$ Polytypes, J. Crystal Growth 52, pp. 146-150.

[10] Nishino S. et al., Production of Large-Area Single-Crystal Wafers of Cubic SiC for Semiconductor Devices, Appl Phys. Lett. 42 (460) (1983). 
[11] MCMullin P. G. et al., Contact Resistance of High Temperature SiC Metallization, Amorphous and Crystalline Silicon Carbide III. Springer Proceedings in Physics, vol. 56 (Springer-Verlag, Berlin, Heidelberg, 1992) pp. 275-282.

[12] PensL G. et al., Silicon Carbide. Recent Results in Physics and in Technology, Festkörperprobleme 30 (Vieweg-Verlag, Wiesbaden, 1990) pp. 133-156.

[13] Cree Research Inc., 2810 Meridian Parkway, Durham, NC 27713.

[14] Edmond J. A. et al., High-Temperature Rectifiers in 6H-Silicon Carbide, Proc. of the 1st Int. High Temperature Electronics Conf. (1991) pp. 500-505.

[15] Davis R. F. et al., Thin Film Deposition and Microelectronic and Optoelectronic Device Fabrication and Characterization in Monocrystalline Alpha and Beta Silicon Carbide, Proc. of the IEEE, vol. 79, n 5 (May 1991).

[16] Kondo Y. et al., High-Temperature Operation of Silicon Carbide MOSFET, Jpn J. Appl. Phys. 26 (1987) 310-311.

[17] Gamal S. H. et al, Power Losses in Silicon and Silicon Carbide Diodes, EPE-MADEP Conference (Florence, 2-6 Sept. 1991). 